\section{ALCOHOL AND THE MOTORIST.}

\section{ALCOHOLIC CONCENTRATION IN URINE AS A TEST OF INTOXICATION.*}

\author{
BY
}

\author{
GODFREY CARTER, M.B.VICT., M.R.C.P.EDIN., \\ D.P.H.LoND.,
}

Lecturer in Forensic Medicine, Sheffield University.

As the use of motor traction has become almost universal, it follows as a natural sequence that measures have become necessary to guard the community against reckless driving, and especially by persons who are under the influence of alcohol. At first sight it would appear that such cases would be few, because the danger, alike to fellow travellers and pedestrians, under these conditions is so serious that elementary instincts of precaution should operate as an overwhelming deterrent.

For a man to drive a fast-running vehicle on a public highway under present crowded conditions whilst drunk is only a degree less culpable than a drunken man being in charge of a railway engine. Disaster is sure to follow.

Since it became part of my official duties to examine all persons arrested on the charge of being intoxicated whilst in charge of motor vehicles within the city boundaries of Sheffield I have been surprised at the number of cases brought to my notice. If I may take our experience, and I think we can, as an average of conditions prevailing elsewhere, I can only affirm that there is throughout the country much undue indulgence by people in charge of cars.

Punishment after conviction should be exemplary. The Government has taken this view, and the Criminal Justice Act, 1925, does not err on the side of leniency. Indeed, many police court practitioners are of opinion that the penalties are so severe that magistrates should hesitate in finding a verdict of guilty, considering that a conviction carries with it a withdrawal of the licence for a considerable period as well as other penalties.

Personally I think the punishment as well as the penalty fits the crime; but I wish that more uniformity existed in the decisions when evidence is of a conclusive character. On one point I think we shall all agree, and that is, that in framing the Act the use of the word "drunk" was unfortunate, and would not have been used had the matter received proper consideration by Parliament. There is no statutory definition of what constitutes being drunk, and therefore all the legal, versus medical, wrangling hinges upon the interpretation placed upon the abnormalities presented at the time of arrest and subsequent examination. Had tho term " under the influence of alcohol " been used many difficulties would have been avoided and the issue materially simplified. The Central Midwives Board, in framing charges, made this change, and all difficulties have sirce disappeared. Also the term "under the influence of drink" appears in the Children's Act of 1908, and in the Inebriates Act of 1898, and they are good and workablo terms.

Safe motoring depends upon a clear and alert mental outlook. Judgement must be poised, nerve cool, and the brain in a position rapidly to assimilate immediate probloms, and arrive at quick and accurate decisions. This delicate nerve balance, poised as it is on the highest brain centres, is the very first function to become disordered by alcohol, and long before the gross inco-ordinations and other symptoms of intoxication develop. Once the latter are in evidence, a person so affected has been running against dalıger signals for some time, but which his brain has been too dulled to read. In order to satisfy counsel and the magistrates that a man may be unfit to drive a

* The opening paper of a discussion in the Section of Forensic Medicine at the Annual Mecting of the British Medical Association, Edinburgh, 1927. Owing to the illness of Professor Harvey Littlejohn the chair was taken by the Right Hon. Earl Russell. motor vehicle, even when ho has moro or less successfully run the gamut of the recognized tests, we have to avoid many possible pitfalls.

As a full and detailed pronouncement upon the tests to be applied, and their clinical significance, have been presented for our guidance by the British Medical Association Committee, it would be a waste of time for me to. go into that subject again now. We are all more or less familiar with them, but no doubt some of us place a greater or less significance upon certain of the tests than do others, or does the Committee.

Personally I think the association of congested conjunctivae with quickness of the pulse very significant as a positive test for inebriety, and I place less value upon the smell of alcohol in the breath than does the Committeo, because it only shows that some alcohol has been consumed, and not how much. Also, when vomiting has occurred, the breath may have only a sour smell replacing the alcoholic odour. Consumption of more than a very small amount, either before or during motoring, is dangerous, and it is only owing to the tolerant way we have come to look upon road problems and dangers that greater resentment has not been aroused.

As 1 have said, the initial lowering of the mental alertness and obscuration of judgement must always be present when there are demonstrable signs of alcoholic indulgence, and a person showing these signs is unfit to be in charge of a motor vehicle, and therefore "drunk" within the meaning of the Act.

Intoxication is, of course, a matter of degree, and passes by insensible gradations from one step downwards to another. Yet it is only when a man has reached the bottom, in a decidedly mixed-up condition, that counsel or bench will adjudge a man drunk. I am glad that the Association's Committee has placed the loss of power of delicate nerve control from indulgence as its definition of being under the influence of alcohol. It is a sound conclusion, and is on parallel lines with the pronouncement of a County Court judge recently given; he stated that " to satisfy him that drunkenness was present in any given case, the skill and judgement normally required in the manipulation of a motor car had been diminished cr impaired as a direct result of the consumption of alcohol. Tho test, so defined, may be difficult to apply, but drivcr's should realize that even a slight disturbance of judgement and response, negligible, prerhaps, in social moments, may spell tragedy in the hazardous business of handling a car."

Have we any further methods than the tests we customarily use to guide us to a conclusion?

I hope it may be pardonable for me to speak for a few moments upon some work recently carried out by Dr. Southgate at the Sheffield University, and in which I took a modest part. I refer to the alcoholic concentration in urine as a test of intoxication. In its report the British Medical Association Committee says that it is of opinion that, while this work is of great value from a scientific point of view, tests depending upon examination of the urine are not practicable for the purpose now under consideration, owing to the conditions limiting their application.

This limitation no doubt refers to difficulties which arise in obtaining and procuring analyses, but $I$ think these difficulties may be gradually. overcome, and are worth applying in such serious cases. An alcoholic secretes a large amount of urine, and does not remain long in a police cell without voiding it. All that is necessary is to make sure that he does not pass it down the w.c. A simple mechanical contrivance can secure this, such as I described in our published communication, and to which I shall make a further reference.

It is obvious that if we can recover alcohol from the urine in estimable quantity by a quick and easily applied method we can at least assert that it has been taken by the mouth within a reasonable time prior to its collection. This disposes of the assertion, made by some on being charged, either that they are total abstainers, or that they have not partaken of more than the usual couple of glasses of beer during the preceding few hours. No textbook with which I am acquainted has. given a satisfactory and 
expeditious method of performing this analysis, and I would refer those who feel interested in the matter to the paper read by Dr. Southgate and myself before the MedicoLegal Society in London and published in the BritisH Medical Journal on March 13th, 1826.

We owe aur present position in this matter chiefly to Mellanby and Southgate. The former has done much work on the estimation of alcohol in the blood, and carried it further to the urine, following upon the lines of Widmark and Miles, and proceeded to establish the ratio between the two. It was found that this ratio stood at the figures 1 to 1.34, showing that the renal epithelium has a selective action for alcohol in secretion. The concentration of alcohol in blood is related to symptoms of intoxication of the central nervous system, and the same applies to urine.

A number of men were experimented upon under arranged conditions, and the following conclusions arrived at. They found that a man of 11 st. weight drinking a solution containing $96 \mathrm{c.cm}$. of alcohol in one drink passes urine containing $200 \mathrm{c.mm}$. of alcohol in $100 \mathrm{c.cm}$. of urine, at its point of maximum concentration. Such a man was moderately intoxicated, and therefore unfit to drive on the road. A concentration of 300 c.mm. per $100 \mathrm{c.cm}$. of urine suggested quite definite intoxication. The results of many subsequent analyses, together with clinical manifestations in each case, were given, and these fully bore out Mellanby and Southgate's figures. Having obtained a sanrple of urine it shourd be quickly bottled to prevent alcoholic evaporation, and once it has reached the analyst a definite result can be obtained within thirty minutes-that is, in time for the opening of the courts. I should add that a Fehling's test should first be performed in order to make sure that there be no atcoholic fermentation from a glycosuric specimen.

I do wish that this examination of the urine for quantitative estimation of alcohol were more frequently applied. If those interested in this snbject will study Dr. Southgate's publication they will see the exact conelusion which can be drawn as regards the probable amount of whisky or beer drunk, the time within which the balk of it had been consumed, and so materially help the court to a correct decision. I may add that as small a quantity as 30 drops of urine will suffice for the purpose of analysis; and the results are given in cubic millimetres per $100 \mathrm{c.cm}$. of urine.

It is advisable, if possible, to obtain two succeeding specimens, noting the interval of time between their being passed," so as to obtain the inclination of the downward curve. From this we can work backward on the chart, and determine the maximum amount that has been present at the material time preceding the arrest.

A simple device for obtaining the specimens is to elamp a receptacle (which can be easily removed) on to the wooden aperture of the w.c. seat. Another plan is a small porcelain urinal fitted into the cell wall at a convenient height. The waste pipe passes through the wall into an unoccupied cell, and discharges into a vessel placed beneath for its reception. By this method no entry into the man's cell is necessary, and a second specimen is easily obtained. Very few drunken persons, I find, will provide a specimen of urine by request. They usually make an excuse, or pass it on to the floor of the cell when alone or when the ordinary w.c. is not available.

[Dr. Carter exhibited copies of Dr. Southgate's charts and commented upon their significance.]

\section{Discussion.}

Dr. E. Bogen (Cincinnati, U.S.A.) referred to the importance of having a quantitative test for drunkenness and described how the alcoholic concentration in the excretions was compared with the findings on elinical examination of 500 persons suspected of drunkenness in the Cincinnati General Hospital. The concentration of alcohol in the breath and urine was tested and compared with the degree of intoxication. The physician was called into court to sustain his evidence. Symptoms of dilated pupils and flushed face were found in less than one-third of these cases, and were principally noted in the moderate groups; persons in a state of coma showed to a high degree constricted pupils and pallor. It was well known that some individuals were able to drink more than others. This was probably due to the delayed absorption of the alcohol and the slower rate of oxidation in persons not habituated. The concentration of alcohol in the breath was the quickest and easiest test. As soon as the disturbing factor of the alcoholic liquor in the mouth was removed the concentration of alcohol in the breath showed a fairly close relation to that in the blood as it passed through the lungs very, easily.

Professor J. T. J. Morrison (Birmingham) said the work on the subject of alcohol in the urine was of high scientific value. It proved the possibility of estimating the concentration of alcohol in the blood; and since this gave a clue to the quantity of alcohol imbibed it might rebut the plea that too little had been taken to produce the alleged effects. He did not expect that the urinary test would become generally adopted because of two practical difficulties-the obtaining of specimens, and their prompt analysis. Moreover, further investigation was required to determine the modifying effects of renal and other diseases on the excretion of alcohol. It was also a serious question whether information of this character, acquired without the consent or even the knowledge of a prisoner, would be admissible in all courts as evidence. It was an axiom of British law that no person was bound to furnish evidence that would incriminate him. When, however, an accused person denied the charge and submitted willingly to examination the matter was on a different footing. A drawback to the procedme was the variation in the effects of a given quantity of alcohol in different persons, and even in the same person in varying circumstances. There was a wide discrepancy between a moderate dinker (still more an abstainer) and a toper. Again, in the case of the same person, alcoholic effects varied with the percentage of alcohol, with the rate of consumption, and with the degree of fullness of the stomach. In comparing different persons, the body weight was a material factor; even more influential was the degree of tolerance induced by habit. "Drunk" was so elastic a term that a rigid definition was better avoided; it connoted various mental, emotional, and muscular evidences of disturbance of the central nervons system dus to alcohol, and there was no single symptom which might not also be caused by disease or trauma. "Under the influence of aleohol" was too vague a phrase for the court. Any quantity had some influence, and a single glass was taken with that purpose in view. The crucial question was how much evidence of disturbance would show the degree of unfitness to be in charge of a motor car which the court would regard as proof of drunkenness. For legal purposes the impairment of functions must be obvious, and only the composite blending of several groups of findings would convince. To determine whether a person had recently taken alcoliol the smell of the breath was a ready test, subject to the well known fallacies. In all cases investigation to ascertain whether the signs and symptoms were due, wholly or partly, to trauma; disease, or malformation was essential. In a medical examination of a man accused of being drunk in charge of a motor car close observation would be made of his general appearance, demeanour, odour of breath, signs of muscular inco-ordination, and time sense relating to the previous few hours. This summary embraced many details relating to face, eyes, and dress; evidences of impaired self-controI, loquacity, emotional display of flippancy, anger, or maudlin sentiment, disregard of social conventions, slurring of speech, clumsiness in sitting down and rising, loss of balance in picking up a coin from the floor. It was not uncommon to find that a man who was the worse for drink would be several hours out in his reckoning of the intervals of time between events of the same evening.

Dr. A. Alerson (Glasgow) said a person might be held to be drunk for the purpose of one offence but not for the purposes of another. In the present case the question which had to be decided was, Had the fitness or effeiency of the individual to be in charge of a motor car witl 
safety to himself and the public been diminished by his consumption of alcohol? The decision rested with the court, and it was unnecessary for the medical witness to formulate a definition of drunkenness. It was well known that certain people were affected by quite small quantities of alcohol, and there was no single clinical sign which was characteristic and which could not be simulated by disease. Each individual sign might be easily demolished during cross-examination. The medical examiner should be able to present a complete picture which would convince the judge or jury that the condition of the accused was due to indulgence in alcohol. It was necessary to eliminate symptoms due to disease, shock, or excitement. In Dr. Allison's experience the shock of an accident or arrest was often sufficient to steady the person, at least temporarily. A symptom to which he attached considerable importance was the readiness with which a person who had overindulged in alcohol fell asleep soon after being placed in the cell. To find a man sleeping heavily ten minutes after the cell door had closed on him was a contraindication of his having suffered from shock or nervousness, and was confirmatory of signs of drunkenness found during the previous examination. It was also helpful in those cases where the man had succeeded temporarily in pulling himself together when first brought to the police station. His practice was to explain the position to the accused and obtain his consent before putting him through any tests for drunkenness. $\mathrm{He}$ was also informed of his right to an independent examination by a doctor of his choicts. Chemical tests might give useful confirmation, but would never altogether replace clinical evidence.

The Charrman (Lord Russell) considered the question more from the legal point of view, and discussed the punishment for drunkenness. In a recent debate the motion was passed that the driver's licence should be suspended for twelve months; this was later modified, and the driver was allowed to appeal for the suspension to be removed after three months. With regard to tests for drunkenness, whatever evidence could be produced as to the alcoholic contents of the urine, or any other tests, the general appearance of the accused must also be taken into consideration. He thought the accused should be given an opportunity of having a medical man of ${ }^{\circ}$ his own choice, but that it was not necessary to warn him of the object of the examination.

Professor J. E. W. MAcFALL (Liverpool) agreed that Dr. Carter's paper was a valuable scientific contribution, but thought it hardly practicable from a police surgeon's standpoint; he doubted whether the excretions of an accused person could be tested without his full knowledge and consent. As a police surgeon he knew the difficulty of certifying borderline cases. He found that each examiner had his own tests and was able to interpret the results of his tests and form an opinion as to whether the incoordination of thought and action as the result of drinking alcohol interfered with the proper performance of the act involved to such an extent as to produce a condition diagnosable as "drunk." One complication was that the state of the accused was often partly due to alcohol and partly due to excitement. He emphasized the importance of time. On two occasions when examining accused persons and deciding to certify them as " not drunk" he found that after some time both became distinctly incapable of driving efficiently. In one case a man changed from having complete control of himself and became an uproarious inebriate. Of the many tests for muscular co-ordination he found the most delicate was to mount a staircase, when the least want of control was indicated by swaying. Perhaps the best test would be for the examiner to be driven by the accused person.

Dr. Carter, in reply, said that a man knew why he was arrested and did not need to be warned of the object of the cxanination, but he agreed that he should be allowed t) send for his own doctor. He was glad to know that Dr. Bogen's conclusions tallied with those formed in this, country.

\section{RADIOLOGY AND DIAGNOSIS OF INTRA- THORACIC TUBERCULOSIS.}

\section{THE IMPORTANCE OF RADIOLOGY IN THE DIAGNOSIS OF PULMONARY TUBERCULOSIS.*}

BY

\author{
H. MORRISTON DAVIES, M.D., M.CH., F.R.C.S., \\ Medical Superintendent, Vale of Clwyd Sanatorium, \\ North Wales.
}

THe title which has been given me to open this discussion contains two subjects: (1) the importance of radiology in the diagnosis of pulmonary tuberculosis, (2) the importance of this as it affects the specialist and general practitioner. Clearly the first of them has to be dealt with before the second can be considered.

Now the diagnosis of pulmonary tuberculosis is not merely a matter of recognizing the presence of the disease, though the recognition of it and the differential diagnosis are of prime importance, and are often matters of great difficulty. Diagnosis must necessarily include, in addition to the type of disease, the character of it; whether, that is to say, it is acute miliary, acute pneumonic, acute ulcerative, or chronic, and to what extent the changes due to the tubercle bacilli predominate, or are complicated by or overshadowed by those due to the secondary organisms; further, what part is played by the mechanical changes. Thirdly, it is imperative, especially if surgical treatment comes into consideration, to know the andtomical extent of the lesions.

While pulmonary tuberculosis may present itself with all the textbook symptoms and signs, in many cases there are problems as to the extent of the activity, the anatomical areas involved, the character of the secondary changes, and the share they take in the picture, which are extremely difficult to solve. The symptoms and signs vary in every case: the clinical and the radiological picture of any patient are as individualistic as are the whorls, loops, and composites on the thumb which are used for identification purposes. There may be but one symptom, such as lassitude or haemorrhage; there may be no sign other than harsh breath sounds. Symptoms such as cough and sputum may be absent from the picture for years. Pyrexia may be an early or late manifestation. While the symptoms are easy to ascertain but sometimes difficult to interpret, the signs may be difficult in both respects. Some patients seem incapable of using their chest or diaphragm so as to make even the normal breath sounds audible through the stethoscope. When it is remembered, further, that there is practically no symptom and practically no sign that cannot be produced at one time or another by every intrathoracic disease, and that, for example, breath sounds can be heard through even a considerable layer of liquid, it is clear that there must be many cases in which it is essential that every means of ascertaining the trouble must be utilized, and that it is most important in all cases to check, control, and correct the clinical findings by the radiological ones.

Of all methods of investigation the clinical examination is unquestionably the most important, but it does not reveal the whole truth, and for much that is hidden we must turn to radioscopy and radiography. There are some few cases even-and they are chiefly those in which the pleural cavity is the seat of the lesion, or is involved secondarily to the disease in the lung-in which one has to rely on radiology for the main part of the evidence.

Radiology has taught us a very great deal about pulmonary tuberculosis. It has corrected the one-time impression that tuberculosis starts most commonly in the apex of the lung - an impression erroneously formed owing to the conduction of the sounds to this region. It has taught us about the limitations of the movements of the ${ }^{*}$ A paper read in opening a discussion in the Section of Tuberculosis a 1927 . S. Vere Pearson, President of al Association, Edinthe chair. 